\title{
LAYERING THE SENSES: EXPLORING AUDIO PRIMACY IN MULTISENSORY CINEMA
}

\author{
$\underline{\text { m.dalgleish2@wlv.ac.uk }}$
}

\begin{abstract}
Numerous authors have argued that cinema is fundamentally visual, while Chion contends that sound and image are so inseparable that, in effect, the soundtrack does not exist. By way of a forwardlooking case study, this paper discusses And a Funeral; a post-anthropocenic retelling of the 1994 rom-com Four Weddings and a Funeral from the perspective of the coffin. Drawing on aspects of prior sound-led films and audio-only video games, And a Funeral proposes a cinematic model in which the auditory is primary but supplemented by other sensory layers (visual and olfactory) that are not necessarily experienced synchronously. The film is 'completed' by each audience member and is highly relevant to diverse access needs. In particular, the film's extended (370 minute) duration encourages alternative, ambient-inspired models of attention and engagement. A range of emergent design issues and possibilities for future work are discussed.
\end{abstract}

\section{INTRODUCTION}

As COVID-19 spread worldwide in Spring 2020, uncertainty about the novel virus and its effects led to the introduction of measures aimed at reducing transmission, deaths and strain on healthcare. These measures included the implementation of "social" distancing, the closure of non-essential businesses, and a requirement to stay at home except for limited stated reasons. ${ }^{1}$ Additionally, the lead author was identified as likely being at heightened risk of severe illness and, in the absence of clear advice, remained at home for an extended period. Emerging from these unexpected circumstances is And a Funeral: a 370-minute, sound-led (but multi-sensory) film that (loosely) retells the 1994 British romantic comedy Four Weddings and a Funeral ${ }^{2}$ from the perspective of a coffin. Particular attention has been paid to the accessibility of the experience.

The effects of pandemic-related isolation have been studied by researchers from numerous different fields, but a psychology study by Bozdağ ${ }^{3}$ is especially relevant here. This study used metaphor to explore individual perceptions of staying home and their relationship to stress, depression and anxiety. Most participants viewed staying at home as confinement and experienced boredom, depression or feelings of helplessness, but a smaller number of participants reported positive aspects. These included seeing staying at home as being vital to helping or protecting others, or in terms of feeling personally safe, but also as a significant opportunity.

Opportunity is closely related to affordance; the term used by design theorist Donald Norman to describe the properties of things (whether physical or virtual) which infer certain actions that users are able to make; or imagine that they are able to make. ${ }^{4}$ Affordances can be further categorised as perceptible, hidden or false, ${ }^{5}$ but a simple example of affordances might be how a ball made of rubber seems to invite the user to bounce it, while a ball made of concrete does not. With Norman's definition of affordances in mind, social isolation or the need to stay at home - even if suddenly and externally imposed - can be seen as a particular (if peculiar) set of affordances for creative production.

The creation of And a Funeral has been informed by numerous bodies of practice and theory. These include audio primacy in audiovisual relationships, found footage film, ambient media, and access for visually impaired audiences. These aspects have traditionally been distinct (and rarely connected) and so will be discussed separately but drawn together as and where appropriate. Following this background, we move on to discuss the film and its implementation, describe emergent design issues, reflect on our experiences, and suggest possibilities for future work. 


\section{RESEARCH BACKGROUND}

\subsection{Audio Primacy in Audiovisual Relationships}

Early approaches to film considered sound as inferior or secondary to image ${ }^{6}$ and related views remained intact over time and across newer media and media transfers. ${ }^{7,8}$ Film sound theorist Michel Chion has taken a different tact, contending that (film) sound and image are melded and fused together to the extent that the soundtrack effectively cannot exist separately from image. ${ }^{9}$ For Chion, this audiovisual fusion is central to the experience of film and the two elements (sound and image) together are more than the sum of their parts: they produce "added value". ${ }^{9}$ One context for Chion's ideas is provided by the comment of Rogers that, as a result of the continued development of new technologies, "audiovisual synchronisation has become easier with every decade that film has existed", ${ }^{10}$ and this ease has led to ubiquitous examples (and the expectation) of seamless audiovisual fusion. In turn, this might help to explain why audio primacy (within audiovisual relationships) has continued to be neglected, leading Ma to question: "why is visuality almost always assumed to be the primary conveyor of meaning, while a film's soundtrack is, at best, the supporting player? An afterthought?"11 Ma focuses on examples by Nam June Paik (Zen for Film), Derek Jarman (Blue) and Cardiff Miller (The Murder of Crows) to develop the concept of "films without images" that, in the 'absence' of (moving) images are defined by their soundtracks. He asks: "If film is understood to be an audio-visual medium, when there are no images in a film, is it still a film? [....] When I ask whether a film without images can still be considered a film, I am also questioning visuality itself."11

There are also examples of audio primacy within more fully audiovisual relationships. Sergei Loznitsa's Blokada (1995) ${ }^{12}$ is a 52-minute documentary created from four hours of archive footage of the siege of Leningrad, punctuated by blank screens that for Youngblood recall the blackouts experienced by the besieged..$^{13}$ Text is used briefly, at the start and end of the film only, and there is no narration. Blokada instead relies on its newly created soundtrack to (re-)animate its sparse (and in many ways) limited images. The soundtrack consists of two fundamental sound types: an overall field of ambience that, unexpectedly prominent and centre in the mix, provides significant atmosphere; and more detailed sound effects such as boots on road and snow; rubble falling as buildings collapse; a handsaw eventually cutting through frozen timber. Both types are diegetic. If the synchronisation between (new) sound and (old) image is considered in terms of Chion's concept of the audiovisual contract, ${ }^{9}$ the match is sufficiently close that the weld should be entirely imperceptible and unnoticed. However, the relative fidelity of the soundtrack (unachievable in the early 1940s) compared to the image, as well as the absence of any obvious technological patina, create an audiovisual juxtaposition that is strangely uncanny: there is a subtle but inescapable sense that sound and image are not out of time, but, rather, out of each other's time.

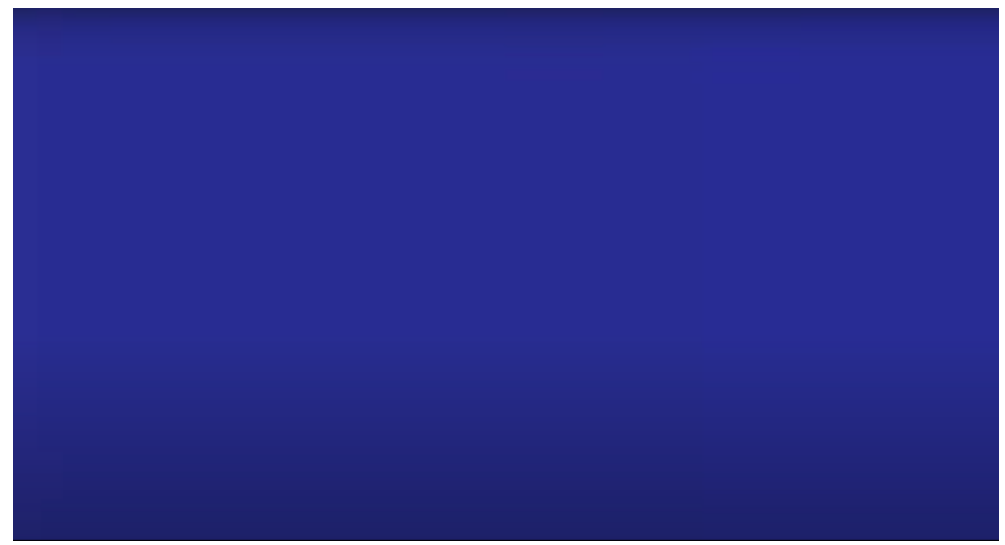

Figure 1. International Klein Blue, as used in Blue (1993).

It is also pertinent to consider Derek Jarman's Blue (1993), ${ }^{14}$ not as one of Ma's examples of a film "without images", ${ }^{11}$ but as an example of audio primacy within an audiovisual relationship. Blue could 
be described as a single, static shot of International Klein Blue accompanied by a soundtrack: yet, such is the importance of the soundtrack to the experience of the film, it could be more accurately described as a soundtrack accompanied by a single shot of International Klein Blue (Fig. 1).

The soundtrack consists of spoken word, music and sound effects. One narrative tells the adventures of Blue as a character and colour. A second narrative describes a (real or imagined) version of Jarman's daily life. The two narratives are interspersed with more dream-like passages. Perhaps the most unusual aspect of the soundtrack is that, accompanied by only a single static image, it is the primary way in which the film's structures and dynamics are delineated. The soundtrack also provides the film's only changing or evolving textures: in addition to the voiceover and numerous sound effects, there is original music from Jarman's regular composer Simon Fisher-Turner, alongside pre-existing music by Coil, Momus, Szymanowski and Satie. ${ }^{15}$

\subsection{Found Footage Film}

Found footage film involves the treatment and use of existent footage as a form of found object. The histories of found footage film are multiple and extensive enough to be beyond the scope of this paper, but numerous texts provide useful overviews for the interested reader. ${ }^{16,17,18}$

In terms of its source material, Just Don't Think I'll Scream (2019), ${ }^{19}$ directed by Frank Beauvais, is perhaps the most directly relevant found footage film (to And a Funeral). Produced while Beauvais lived alone in an isolated village after the end of a relationship and shortly after the 2015 Paris terror attacks, it is crafted from some 400 different fragments of existing films. ${ }^{20}$ The construction of the film is described by Beauvais as a kind of puzzle involving fitting the visual clips to a dictaphone-recorded spoken narrative, while trying to strike a balance between the poetic and the illustrative. ${ }^{20}$ Just Don't Think I'll Scream is also strongly soundtrack-led in that its disparate visual material (stripped of its original sound) is effectively glued together only by voiceover; and it's the soundtrack that gives consistency and thus, in a narrative sense, gives meaning to the paired images.

Another recent found footage film, La Película Infinita (2018), ${ }^{21}$ by director and film museum curator Leandro Listorti, is made entirely from fragments of abandoned Argentinian films. Emotively described by its publisher as "a cinematic Frankenstein", 22 it is prescient in how it re-presents archival footage in an entirely new context, without relying on the original context being identifiable (the source films remain unseen). Particularly pertinent is how La Película Infinita leaves the viewer to construct their own meaning from the unreliable and often reduced information provided. Sound is sometimes (but not always) stripped away to leave a jarring absence of sound, for instance the soundless dialogue at 00:29:20, or the strangely silent reprise at 00:53:23. Other scenes do include Foley and dialogue. It is initially ambiguous as to whether these sounds are lifted from the original soundtrack or contemporary additions. For instance, the sizzling, crackling sound that emerges out of the noise floor at 00:01:35 could be original, but it is unusually prominent, and it is difficult to be certain. By the time the same sound reappears at 00:39.37 but its apparent source is no longer near, it is more certain that the audiovisual relationship is being manipulated. Other passages, both with and without dialogue, ambient sound and sound effects, are buried in abrasive musical drone that does little to serve any of the usual conventions of film music. If the soundtrack is never able to be trusted or relied upon, its frequent departures from the naturalistic and expected help to grab and hold the attention. Whether despite or because of the instability of the (soundtrack-led) audiovisual construction, highly interpretative narratives are suggested, far beyond the possibilities of the image-fragments alone.

Other examples of audio primacy and manipulation of the audiovisual relationship can be identified in found footage comedy. What's Up, Tiger Lily? (1966) ${ }^{23}$ cannibalises two Japanese Bond parody films. ${ }^{24,25}$ These were then edited together and redubbed in English to create a new narrative, unrelated to the originals, about an egg salad recipe. Dead Men Don't Wear Plaid (1982) ${ }^{26}$ is similar in that it involves overdubbed and re-edited footage from more than twenty classic film noir films, positioning them alongside original sequences featuring actor and comic Steve Martin. Both films rely on similar devices to achieve comedic effect: they depend on an audiovisual weld that is obviously an artificial construction. However, perhaps because there is so little attempt at conceit (i.e. 
concealment of the join), or because of the shifted expectations of the genre, audiences are still able to suspend disbelief and buy into what Chion terms the audiovisual contract. ${ }^{9}$

\subsection{Ambient Media}

Stepping back from the audiovisual experience itself, it's useful to consider the broader environment in which the experience takes place. Ambient television is a term used by Anna McCarthy in relation to television that is experienced outside of a domestic environment. ${ }^{27}$ For McCarthy, the external (i.e. beyond the domestic) aspect of ambient experience is significant because it uncouples the screen from the repetitive and highly gendered rhythms of labour and the home. ${ }^{27}$ If the old relations are inevitably supplanted by other, sometimes equally complex relations between time and space; and these relations can vary considerably from place to place, ambient encounters have the potential to foster different expectations around viewing and experience. ${ }^{27}$

The potential for different kinds of audiovisual encounters has only increased over the period where mobile and tablet devices have become ubiquitous. As Rigby et al. noted in 2014, "content is moving out of the living room and onto mobile devices - viewers are now watching when and where it suits them, on devices of differing sizes." 28 There is increasing evidence not only that people are watching in a range of devices, but also that devices are shaping what is watched (some television is more likely to be watched on one device type than another), and who is watching. ${ }^{29}$

\subsection{Access and Visual Impairment}

Engaging with audiovisual media can mean that people with disabilities encounter barriers to access. The barriers faced by people with disabilities are often considered in terms of either medical or social models of disability. The medical model of disability is long running to the point of entrenchment and conceives of disability as a problem existing in a person's body: it is the individual and not society who has the problem. The individual is thought to require treatment to "fix" the disability and restore "normal" functioning, or to "overcome" the disability. ${ }^{30,31}$ A related aspect of the medical model is to consider disability in terms of (in)ability to contribute productively; and this in turn may be used to determine an individual's eligibility for financial or other assistance.

The 1970s onwards saw the medical model challenged by the social model of UPIAS, amongst others. ${ }^{32,33}$ UPIAS proposed that, rather than an individual or bodily issue, people are disabled by the attitudes of society. ${ }^{34}$ In other words, it is society that creates barriers or obstacles which are disabling. The social model has never fully replaced the medical model (particularly at a state level); and Owens contends that the social model is itself outdated, ${ }^{35}$ but it nevertheless continues to be adopted by a wide variety of disability organisations. ${ }^{36}$

In 2018-19, disabled people made up at least $8 \%$ of National Portfolio Organisation (NPO) arts audiences ${ }^{37}$ notably less than the $22 \%$ of UK population who identify as disabled, ${ }^{38}$ but still a significant proportion of total audiences. These findings come some five-to-six years after the first (ACE-supported) SHAPE report stated that "[o]rganisations have made great strides in improving their access provisions in recent years", ${ }^{39}$ while also noting that disabled people "still face preventable barriers in accessing arts and cultural events, including transportation issues, price of tickets, lack of information and support at venues." 39

Visual impairments are inherently diverse, and each experience of visual impairment is unique, but at least 2.2 billion people worldwide have a visual impairment of some kind. ${ }^{40}$ Prior to the pandemic at least, there had been significant progress around access for blind and visually impaired audiences at live arts and entertainment venues; primarily via the provision of live audio description (AD) services. ${ }^{41}$ Comparable services are also sometimes available for film and television, although they are not usually delivered live. ${ }^{42}$

$A D$ for theatre is a branch of $A D$ that translates the visual aspects of a performance into a spoken commentary that fits between gaps in actors' dialogue. ${ }^{43}$ Although not universally adopted, AD for theatre had become established in the UK and $40 \%$ of theatres offered at least one audio-described 
performance between 2013 and $2016 .{ }^{44}$ This provision might have been expected to further grow and develop, ${ }^{45}$ but the COVID-19 pandemic has created uncertainty around the futures of many venues, ${ }^{46}$ and additional difficulties for disabled audiences in particular. For instance, Miller draws on recent survey data to highlight significant disparity between the attitudes of disabled and non-disabled people in returning to cultural venues after the end of the first lockdown in England. 47,48

Perhaps due to the difficulties posed by the medium in terms of variety, nonlinearity and openendedness, $A D$ for video games is a less mature space than $A D$ for theatre, but there is increasing interest in the area. ${ }^{49}$ Nevertheless, video games also hint at a potential alternative to AD in the form of audio-only games. Where AD must fit into gaps in dialogue and its "standard" delivery can be likened to a neutral, newsreader, ${ }^{50,51}$ sound in audio-only games is typically used far more extensively but also more creatively; and (as it's not pitting dialogue against description) different kinds of sounds can be layered and overlap but, at the same time, remain intelligible and perform different roles. For instance, the audio-only flight simulator game EuroFly ${ }^{52}$ uses sound to simultaneously convey complex information to the player relating to physical and mechanical state, navigation, environment, and peer (etc.) information.

\section{AND A FUNERAL: AN OVERVIEW}

Our previous work explored issues around access and accessibility, ${ }^{53}$ but at the onset of the pandemic it became apparent that the tangible, hands-on aspects of the project made it difficult to continue. Thus, And a Funeral arose out of exploring of what is possible under these (for us at least) unprecedented circumstances: just as the OUvroir de LItterature POtentielle (OuLiPo) movement sought to free literature by adopting unusually tight constraints, ${ }^{54}$ And a Funeral reimagined the apparent limitations of the pandemic as an Oulipolean set of affordances for doing something different(ly). Nevertheless, as it reimagines Four Weddings and a Funeral for a post-anthropocenic world, it eschews the ensemble structure and heavy characterisation of the Richard Curtis-penned original script in favour of a single focal point: a (non-vitalist, inanimate) wooden coffin.

The Anthropocene is the present era of Earth's history; an era that has seen the planet's geologic features (see Fig. 2 for an example) and, ultimately, its liveability, fundamentally altered by human activities. ${ }^{55}$ For Barad, these changes are closely connected to human mastery of the atom and its potential, not only for destruction, but epochal shift, commenting that the "hands of time indeterminately positioned as creeping toward the midnight of human and more-than-human existence, moving and no longer moving." 56 The post-anthropocene then, is characterised life after humans: a shift that, in 2020 , as nature rebalanced, ${ }^{57}$ became somewhat more imaginable.

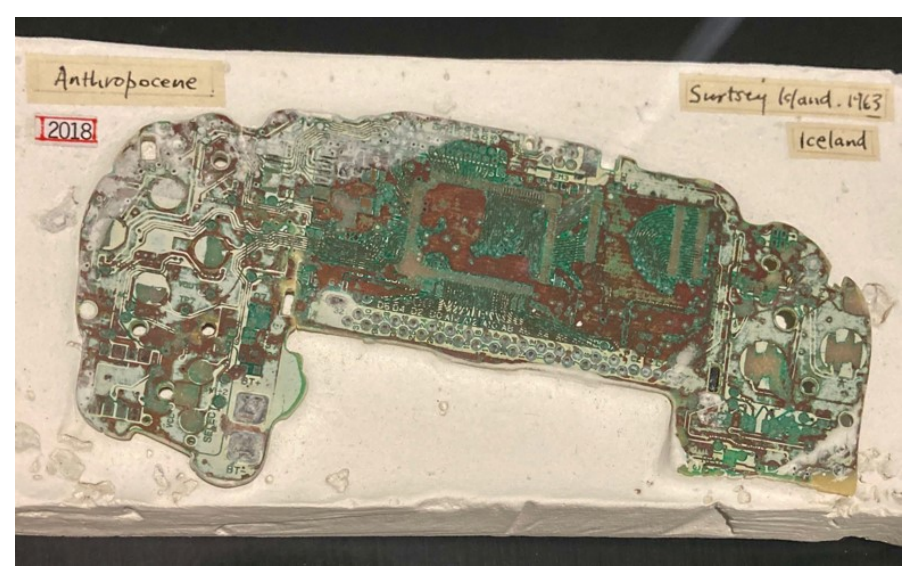

Figure 2. Human e-waste found in the geological structure of the remote volcanic island of Surtsey, Iceland. Part of the Two Islands exhibition at the Lapworth Museum, University of Birmingham.

In more concrete terms, And a Funeral is designed to be experienced on a range of personal devices and its duration of 370 minutes is intended to resist and discourage conventional modes of engaging 
with and experiencing film and television. If television series of this length are relatively common and, in an age of streaming, can be binge-watched in one session, conventional modes of engagement are also discouraged by a combination of relentlessness (there are no pauses or intermissions) and extremely slow pacing overall: some scenes extend to over ten minutes duration and some images move so slowly that motion and change are only barely perceptible. The aim is to destabilise expectations around engagement; and reduce barriers (in the social sense) to access, so that new ways of engaging can be found. For instance, the impossibility of close concentration for over six hours may encourage audiences to dip in and out, and thereby experience the film in a more ambientlike way. Crucially, this need not be a lesser or lessened experience: La Película Infinita, ${ }^{21}$ for instance, hints at the potential for an audience to piece together an individualised narrative from fragments of disparate and relatively reduced audiovisual information.

The hope is that new ways of engaging can enable new (for instance, previously excluded) audiences to engage. For example, a model that encourages dipping in and out over continuous focused consumption may be particularly relevant to people with a sitting disability. Sitting disabilities have numerous causes, including lower back pain, sciatica, pelvic pain and Hidradenitis suppurativa. They are characterised by being unable to sit, and in some instances also stand, for extended periods of time. ${ }^{58}$ The slowness of And a Funeral is also relevant to Akinetopsia; an uncommon visual impairment that impacts the ability to perceive visual motion. ${ }^{59}$ The condition does not affect the perception of stationary objects; and thus the slowed to near-static images that make up significant parts of And a Funeral may help to improve the visual acuity of the film (and the experience) for people with Akinetopsia. In these respects, the duration and slowness of And a Funeral can be seen as accessible design features; affordances that support and foster more diverse kinds of access. Below the macro-level, the film is multisensory. It consists of (moving) images, soundtrack, and olfactory augmentation. These aspects will now be discussed in turn.

\section{1 (Moving) Images}

The images used in And a Funeral are a mixture of found and original footage, punctuated by singlecolour screens. The found footage consists of two types of material: 20TB of films (black and white and colour) collected for a variety of other purposes (study, recreation, illustrating lectures, etc.) over the last decade, plus approximately 600 hours of footage recorded over the last year-and-a-half from publicly accessible IP cameras located around the world. The two types of found footage are intended to be complimentary: snapshots distributed in time (or rather, film history) and snapshots distributed in space, respectively. Both types are stripped of their original soundtracks.

For the most part, feature-length films are used so that, compared to shorts, there is increased possibility for selecting material from incidental or less recognisable passages. The films used span a period of 118 years (1903-2021). Images of well-known actors, particularly in closeup, are avoided. This is partly due to the post-anthropocenic script, but also that, as Beauvais notes, images of stars are so highly fetishised in mainstream cinema and its history; and this fetishisation is closely tied to a studio system increasingly recognised as problematic and harmful. ${ }^{20,60}$

The IP camera footage explores the potential of internet-connected devices to act as lenses that enable a remote viewer to see into a variety of 'dangerous' worlds beyond the walls of the home. Viewpoints include: the emptied streets of Wuhan; the Chernobyl Nuclear Power Plant Zone of Alienation; woodland around Mount Fuji; volcanic activity in Iceland; the slopes of Mount Etna; and a remote desert in Kazakhstan. All are static, without explicit human presence, and cropped to remove any production information (time and date, channel logos, etc.).

The original footage was filmed between April and June 2020. The restrictions and health guidance in place at this time demanded that this original footage is a mixture of the domestic and the on-foot hyperlocal (amplified by mobility impairment); only interrupted by a cross-county car journey to a healthcare appointment (Fig. 3). If initially unintentionally, the body of original footage, filmed at a rate of one clip per day, forms a personal diary of the first lockdown. 


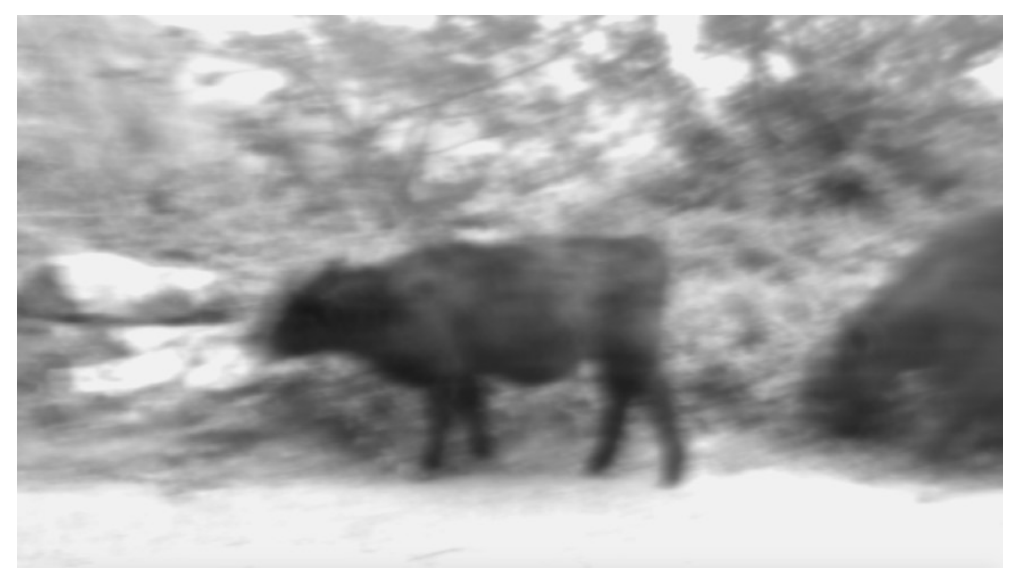

Figure 3. A still from original footage shot in June 2020.

Footage types are juxtaposed, combined and overlapped non-preciously. Where necessary, external video feedback processing is used to greatly extend the duration of original and found footage, and the results then re-recorded. The feedback acts as what Crutchfield calls a dissipative dynamical system; 61 a specialised kind of "space-time simulation" that (in this use case) dissolves the previously discrete jumps between one frame and the next. This process is not free of artefacts; the properties of the source images are also transformed in ways that cannot always be predicted.

More generally, all images are treated in ways that may aid and improve the experience of visual impaired audiences. The processes applied vary throughout the film but include: thresholding operations; image simplification; contrast enhancement; colour and gradient remapping; magnification and cropping. Coverage here cannot hope to be exhaustive, but the most common causes of visual impairment include cataracts, macular degeneration and glaucoma. ${ }^{62}$ Pun et al. suggest that the above are especially relevant where visual impairment is well characterised either spatially or in the frequency domain. ${ }^{63}$ For instance, the effects of cataracts are described by IrokuMalize and Kirsch and simulated by Marmor, ${ }^{64,65}$ and include limited colour perception and reduced visual acuity. The use of image simplification and enhanced contrast is not a panacea but can help to counter some of these effects by increasing image sharpness and clarity.

Other conditions relevant to the design of And a Funeral include age-related macular degeneration (AMD) and glaucoma. Earlier stages of AMD cause blurred or reduced central vision but, in its advanced form, AMD can produce a blind spot at the centre of the visual field. ${ }^{66}$ Glaucoma is a group of eye conditions involving damage to the optic nerve. Glaucoma can initially lead to a gradual or sudden or loss of the peripheral visual field, but, left untreated, can eventually lead to tunnel vision. ${ }^{67}$

Cropping and magnification are used to create images that, for most of the film, operate in either the centre of the screen or at its periphery (the idea that no-one experiences everything). However, in two specific scenes (a hospital/death scene and a burial/cremation scene), one narrative unfolds in the centre of the screen while, simultaneously, an entirely different narrative plays out at the periphery (Fig. 4). The idea is that this formatting will be relevant to people with AMD (who may access only the peripheral image) or glaucoma (who may see only the centre image), but at the same time be interesting for all. In this sense it offers a particular take on universal design, or the idea that something can be designed in such a way that it can be accessed and (productively) used by all who encounter it. 68

Footage is punctuated by screens consisting of a single shade of chromatic or non-chromatic grey. The specific shade of grey is determined programmatically: Processing, ${ }^{69}$ a free graphics library and $I D E$, is used to find the average pixel colour value for all constituent images in a scene, and this determines the colour value used. 


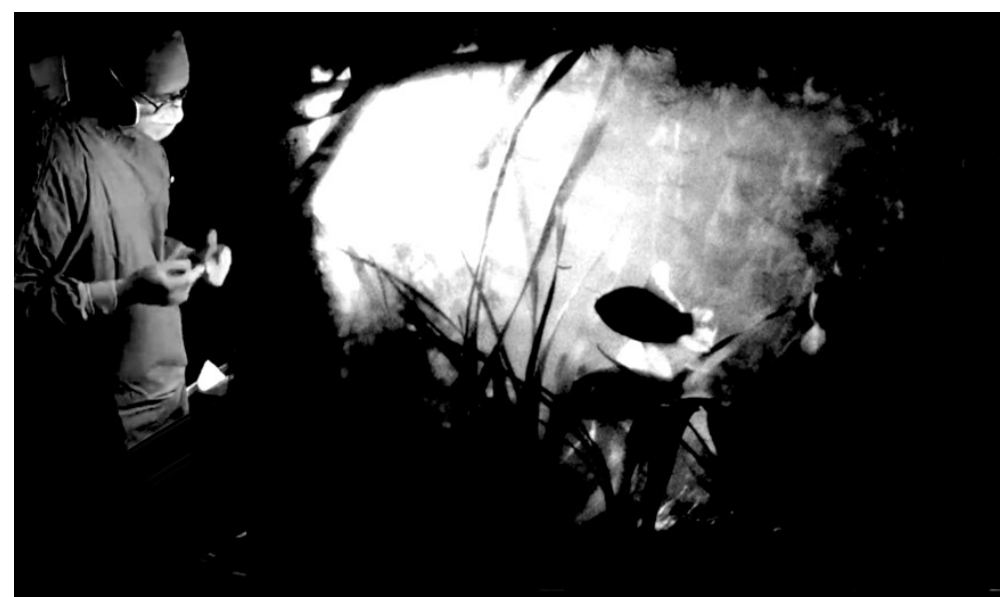

Figure 4. A still from And a Funeral showing dual centre and peripheral composition.

Low vision generally makes text difficult to read ${ }^{70}$ and so these single-colour screens are not adorned by text. Indeed, other than to present the title of the film, And a Funeral eschews the use of text entirely: even in the case of the title text, it is also read aloud at the same time.

\subsection{Soundtrack}

All images in And a Funeral have either been recorded without sound or had their original sound removed before use. However, instead of the soundtrack being created at the same time as the images, or added to the images ex post facto, the soundtrack was created immediately after the production of the script, before any images were created, selected or organised.

The frequency spectrum able to be perceived by the human ear; and the power intensity it can tolerate, are usually considered to considerably surpass the comparative capabilities of the human eye. These differences can be even more pronounced in the presence of visual impairment. The resolution and dynamic range of the visual modality can also be (intentionally) limited by the processing intended to make the images more accessible. Rather than a limitation, it can be seen as an opportunity to shift responsibility towards the auditory and the soundtrack: In other words, the structure of And a Funeral and the slowness and processing of many of its images mean that the soundtrack has more responsibility in terms of, for instance, movement, pacing, narrative and detail.

With the script detailing the number and nature of the film's constituent scenes, extended passages of sound were created to realise each scene. Without using dialogue or relying on voiceover, the intention was for each passage to convey the basic narrative, the environment or environments in which the narrative is located, and any information that would typically be audio described.

\footnotetext{
Substituting traditional Hollywood scoring and mixing practices with a more adventurous language and methods that recognize the interconnectedness of all soundtrack elements, this trend has produced soundtracks in which it is difficult to tell the difference between score and ambient sound, where pieces of pre-existing musique concrète or electroacoustic music are merged with diegetic sound, sound effects are absorbed by the score or treated as music, and diegetic sound is treated as musique concrète. Over the last few decades this trend has relativized the boundary between scoring and sound design and subverted long-established hierarchical relationships between dialogue, music, and sound effects, challenging the modes of perception shaped by classical soundtrack practices. ${ }^{71}$
}

The soundtrack is what Kulezic-Wilson (above) terms "integrated", blurring the traditional distinction between music and sound design. ${ }^{71}$ This means in practice that conventional (film) musical features are almost entirely absent. Traditional musical instruments are used, but only as part of a broader palette of sound design tools that include ambient and contact and microphones, hydrophones, an 
EMF sniffer, and various shortwave and software-defined radios. These are then subjected to processing in software (Max, Pure Data and Logic Pro X) and hardware (a Eurorack synthesizer and outboard compression). Rather than try to use sound design musically; for example, to replace traditional musical instrument timbres or textures, the emphasis is on more abstract shaping of sound as material, and on sound as an environment able to be experienced and inhabited.

The images used in And a Funeral present a wide range of locations, but, at the same time, few are widely recognisable. Thus, this sonic environment has both responsibility and creative freedom in terms of creating a coherent and immersive sense of place. A sense of place can refer to the perceived sensation of a place or the particular character or qualities of a place. For Chion, ambient sounds can give definition to place through their pervasive presence, but these "territory sounds" are usually relatively unnoticed, unstudied and in the background. In the case of And a Funeral they are a primary function of the soundtrack, but there is little attempt disguise that they are composed. More important is its presence. Presence relates to the sense of "being there" in relation to a virtual environment. Specifically, it relates to the subjective experience of being in one (virtual) environment (in this case the sound world of the film), while not physically part of it; the result of the cognitive and perceptual systems being convinced that they are somewhere other than their physical location. ${ }^{72}$

The only sound outside of this sonic environment is a relatively short (7 minute) passage of voiceoverturned $A D$ over opening sequences of the film. However, instead of more extensive use of $A D$, details that have the potential to be audio described are instead conveyed through the sonic environment described above and the use of informational sounds. A more extensive development of previous work by the author that used information sound in theatre, the aim of this shift is to overcome some of the limitations inherent to standard $A D$ in terms of temporal freedom (not having to fit between gaps in dialogue), the potential for creative interpretation, and the cost of live AD provision. ${ }^{50}$

\subsection{Olfactory Augmentation}

Although there has been considerable recent interest in crossmodal correspondence and olfactorycolour cross-modality has been explored, ${ }^{73}$ Spence argues that matching of scents and music is "one of the least frequently explored combinations of senses in an entertainment and multisensory experiential design context." ${ }^{44}$ And a Funeral explores the use of olfactory stimuli (odours) to highlight and emphasise selected artefacts in the film. Nine odours are presented in a $3 \times 3$ array of screw-top jars. The nine odours are: oakmoss (wet forest); oak extract; birch tar (leather); timber propanol (sawdust); carbolic acid (hospital disinfectant); cadaverine (corpse); lily extract; and frankincense (incense). Unlike the fixed audiovisual relationship (i.e. synchronisation), the sampling of the odours is detached from the timeframe of the audiovisual relationship. Effectively taken out of time, each audience member can construct their own multisensory experience based on complimentary or contradictory crossmodalities (or a mixture of the two).

\section{DISCUSSION AND FUTURE WORK}

This paper has introduced and provided background to And a Funeral, drawing together and making links between several usually separate areas. It has emphasised crossover between aspects such as audiovisual relationships, accessibility and extra-domestic engagement with media. Against this backdrop, the ideas that underpin the film, and the film's structure and makeup have then been discussed. In particular, the extra-auditory qualities of And a Funeral have necessitated shifting many of the functions and responsibilities that are usually visual (or conveyed by images), over to the soundtrack. There is some precedent for this in earlier work by (for instance) Jarman and Listori, amongst others, but at present it is difficult to know the most appropriate and widely accessible sensory and experiential balance at present and thus this film functions as a kind of exploratory prototype. However, if And a Funeral is, to a significant extent, a product of the COVID-19 pandemic (and, less directly, about it), the pandemic and its duration have also significantly impacted our ability to evaluate these aspects. The most immediate possibility for future work is therefore to carry out a user study, ideally in situ and with diverse audiences, in order to draw out their experiences, opinions 
and preferences (for instance around sensory balance and presence). This nevertheless continues to pose some difficulties in that, although most formal restrictions on activities have recently ended, some of the intended audience for the film are likely to be clinically vulnerable or, as Miller identified, ${ }^{46}$ have concerns about being part of an audience.

As And a Funeral has started to map out and explore changed audiovisual relationships and stretch out to consider the other senses, one of the most interesting crossmodalities has been between the auditory and the olfactory. The practicalities of presenting olfactory stimuli may ultimately discourage more mainstream interest and uptake, but they offer an unusual and fascinating supporting layer. By giving freedom in the timeline of the film as to when they are experienced, some quite unexpected combinations can be created. For instance, it seems obvious that oakmoss and oak extract are to be experienced at the same time as the extended forest scene. However, if these odours are sampled later, during the coffin-making scene, the effect is profoundly different: the scents become a lament for the lives of trees lost to human activity.

Artificial haptic stimuli are not currently employed, in order to maximise compatibility across a range of devices and screen sizes (or avoid the need for additional hardware), but this is another potential area for future work. Haptics could, for instance, be used to supplement informational sound by adding a more palpably physical aspect.

\section{REFERENCES}

1. E. Bendavid, C. Oh, J. Bhattacharya and J.P.A. loannidis, 'Assessing mandatory stay-athome and business closure effects on the spread of COVID-19', European Journal of Clinical Investigation. 51(e13484). (2021).

2. M. Newell (Director), Four Weddings and a Funeral [Film], The Rank Organisation. (1994).

3. F. Bozdağ, 'The psychological effects of staying home due to the COVID-19 pandemic', The Journal of General Psychology. 148(3) 226-248. (2021).

4. $\quad$ D.A. Norman. The Design of Everyday Things, $1^{\text {st }}$ ed Doubleday. (1989).

5. W.W. Gaver, Technology affordances, Proc. $9^{\text {th }}$ CHI, 79-84. New Orleans (1991).

6. R. Arnheim. Film As Art, University of California Press. (1957).

7. J. Richardson, C. Gorbman and C. Vernallis, The Oxford Handbook of New Audiovisual Aesthetics, Oxford University Press. (2013).

8. R. Altman, Sound Theory, Sound Practice, Routledge. (1992).

9. M. Chion, Audio-vision: Sound on Screen, $1^{\text {st }}$ ed Columbia University Press. (1994).

10. Rogers, H. and Barham, J., The Music and Sound of Experimental Film, Oxford University Press, 1-4. (2017).

11. M.-Y.S. Ma, There is No Soundtrack: Rethinking Art, Media, and the Audio-visual Contract, $1^{\text {st }}$ ed Manchester University Press. (2020).

12. S. Loznitsa (Director), Blokada [Film], New Wave Films. (1995).

13. D.J. Youngblood, 'Review: A Chronicle for Our Time: Sergei Loznitsa's "The Blockade" (2006)', The Russian Review. 66 693-698. (October 2007).

14. D. Jarman (Director), Blue [Film], Zeitgeist Films. (1993).

15. A. Wilson, 'Blue', https://www.tate.org.uk/art/artworks/jarman-blue-t14555 [Last accessed on 11 October 2021].

16. W.C. Wees, Recycled Images: The Art and Politics of Found Footage Films, Anthology Film Archives. (1993).

17. J. Baron, The Archive Effect: Found Footage and the Audiovisual Experience of History, Routledge. (2013).

18. J. Guldemond, M. Bloemheuval and F. Milani, Found Footage: Cinema Exposed, AUP Popular Science. (2014).

19. F. Beauvais (Director), Just Don't Think I'Il Scream [Film], KimStim. (2019).

20. S. Pettengill, 'This Sweet Sickness: Frank Beauvais On His Obsessive, Archival-Based Memoir, Just Don't Think I'll Scream', Filmmaker Magazine, https://filmmakermagazine.com/109365-this-sweet-sickness/ [Last accessed on 22 September 2021]. 
21. L. Listori (Director), La Película Infinita [Film], Punctum Sales. (2018).

22. Punctum Sales, 'The Endless Film', https://punctumsales.com/pelcula/the-infinite-movie/ [Last accessed on 21 September 2021].

23. W. Allen (Director), What's Up, Tiger Lily? [Film], American International Pictures. (1966).

24. T. Tsuboshima (Director), Kokusai Himitsu Keisatsu: Kayaku no Taru [Film], Toho Company. (1964).

25. S. Taniguchi (Director), Kokusai Himitsu Keisatsu: Kagi no Kagi [Film], Toho Company. (1965).

26. C. Reiner (Director), Dead Men Don't Wear Plaid [Film], Universal Pictures. (1982).

27. A. McCarthy, Ambient Television, The MIT Press. (2001).

28. J. Rigby, D. Brumby, A. Cox and S.J.J. Gould, Watching Movies on Netflix: Investigating the Effect of Screen Size on Viewer Immersion, Proc. of 18th International Conference on Human-Computer Interaction with Mobile Devices and Services, 714-721. Florence (2016).

29. Broadcasters' Audience Research Board, 'The Viewing Report: Our annual exploration of the UK's viewing habits 2020', https://www.barb.co.uk/download/?file=/wpcontent/uploads/2020/05/Barb-Viewing-Report-2020_32pp_spreads_FINAL.pdf [Last accessed on 03 October 2021].

30. M. Solomon, J.R. Simon, and H. Kincaid (eds), The Routledge Companion to Philosophy of Medicine, $1^{\text {st }}$ ed Routledge. (2016).

31. S. Goering, 'Rethinking Disability: The Social Model of Disability and Chronic Disease', Curr Rev Musculoskelet Med, 8(2) 134-8. (June 2015).

32. UPIAS, Fundamental Principles of Disability, Union of the Physically Impaired Against Segregation. (1975).

33. D. Locker, Disability and Disadvantage, Tavistock. (1983).

34. L.J. Davis (ed), The Disability Studies Reader, 1'st Ed Routledge, 266-273. (2016).

35. J. Owens, 'Exploring the critiques of the social model of disability: the transformative possibility of Arendt's notion of power', sociology of health \& illness. 37(3) 385-403. (2015).

36. E. Pullen, D. Jackson and M. Silk, 'Watching disability: UK audience perceptions of the Paralympics, equality and social change', European Journal of Communication. 35(5) 469483. (2020).

37. Arts Council England, 'Equality, Diversity and the Creative Case: A Data Report, 2018-19', https://www.artscouncil.org.uk/sites/default/files/download-

file/Equality_Diversity_and_the_Creative_Case_A_Data_Report_201920_LP.pdf [Last accessed on 17 September 2021].

38. Statista, 'Prevalence of disability in the United Kingdom (UK) in 2019/20', https://www.statista.com/statistics/449271/disability-prevalence-region-united-kingdom-uk/ [Last accessed on 17 September 2021].

39. SHAPE, 'Understanding Disabled People as Audiences 2012-13', https://www.culturehive.co.uk/wp-

content/uploads/2020/10/shape understanding_disabled_people_as audiences_2012-132.pdf [Last accessed on 26 September 2021].

40. World Health Organization, 'Eye care, vision care, vision impairment and blindness', https://www.who.int/health-topics/blindness-and-vision-loss\#tab=tab_1 [Last accessed on 14 August 2021].

41. A. Holland, Audio Description in the Theatre and the Visual Arts: Images into Words, in J.D Cintas and G. Anderman (eds), Audiovisual Translation, Palgrave Macmillan, 170-177. (2009).

42. J. Snyder, The Visual Made Verbal: A Comprehensive Training Manual and Guide to the History and Applications of Audio Description, Dog Ear Publishing. (2020).

43. L. Fryer, An Introduction to Audio Description, Routledge. (2016).

44. M. Cock, 'Dark Performances', Arts Professional, https://www.artsprofessional.co.uk/magazine/article/dark-performances [Last accessed on 11 October 2021].

45. S. Braun and K. Starr, Innovation in Audio Description Research, Routledge. (2020).

46. OECD, 'Culture shock: COVID-19 and the cultural and creative sectors', https://www.oecd.org/coronavirus/policy-responses/culture-shock-covid-19-and-the-culturaland-creative-sectors-08da9e0e/ [Last accessed on 19 August 2021]. 
47. A. Miller, 'Slump in disabled audiences' confidence presents major problem for the arts sector', http://s3-eu-west-1.amazonaws.com/supercool-indigo/Disabled-audiences-Act-2wave-1-Andrew-Miller.pdf [Last accessed on 19 September 2021].

48. Indigo, 'Act 2 National Audience Research,' http://s3-eu-west-1.amazonaws.com/supercoolindigo/Full-report-Act-2-wave-1-c-Indigo.pdf [Last accessed on 19 September 2021].

49. R. Lloyd, 'Developing games for low-vision players', https://www.gamesindustry.biz/articles/2021-05-11-developing-games-for-low-vision-players [Last accessed on 29 August 2021].

50. A. Walczak and L. Fryer, 'Creative description: The impact of audio description style on presence in visually impaired audiences', British Journal of Visual Impairment, 35(1) 6-17. (2017).

51. M. Dalgleish and N. Reading, Seeing with one's own ears: soundtrack as interface for theatre, in I. Soveral and F. Pombo (eds), Synchresis: Audio Vision Tales, Universidade de Aveiro. (2019).

52. Kissoft, 'Eurofly', https://www.eurofly.stefankiss.sk/ [Last accessed on 12 October 2021].

53. M. Dalgleish and S. Whitfield, Sound Objects: Exploring Embedded Computing for Procedural Audio in Theatre, in R. Hepworth-Sawyer, J. Paterson and R. Toulson, R. (eds), Innovation in Music: Future Opportunities, $1^{\text {st }}$ ed Routledge. (2021).

54. L. Esposito and S. Elkin, End of Oulipo?: An attempt to exhaust a movement, Zero Books. (2013).

55. S. Lewis and M. Maslin, 'Defining the Anthropocene', Nature. 519 171-180. (2015).

56. K. Barad, No Small Matter: Mushroom Clouds, Ecologies of Nothingness, and Strange Topologies of Spacetimemattering, in A.L. Tsing, H.A. Swanson, E. Gan and N. Bubandt (eds), Arts of Living on a Damaged Planet: Ghosts and Monsters of the Anthropocene, University of Minnesota Press. (2017).

57. S. Arora, K.D. Bhaukhandi and P.K. Mishra, 'Coronavirus lockdown helped the environment to bounce back', Sci Total Environ, 742 (10 November 2020).

58. P. Lampard and T. Bunsell, 'Falling through the cracks: recognising sitting disabilities', Disability \& Society. 34(3), 470-490. (2019).

59. S. Zeki, 'Cerebral Akinetopsia (Visual Motion Blindness): A Review, Brain', 114(2), 811-824. (April 1991).

60. D. Jones and J.K. Pringle, 'Unmanageable Inequalities: Sexism in the Film Industry', The Sociological Review. 63(1) 37-49. (2015).

61. J.P. Crutchfield, 'Space-time dynamics in video feedback', Physica. 10D 229-245. (1984).

62. World Health Organization, 'A Simplified Cataract Grading System', http://apps.who.int/iris/bitstream/handle/10665/67221/WHO_PBL_01.81.pdf;jsessionid=FE5 49F77BC196404227AC659685D91D6?sequence=1 [Last accessed on 04 September 2021].

63. T. Pun, P. Roth, G. Bologna, K. Moustakas and D. Tzovaras, 'Image and Video Processing for Visually Handicapped People', J of Image and Video Proc. 2007(4) 1-12. (2007).

64. T. Iroku-Malize and S. Kirsch, 'Eye Conditions in Older Adults: Cataracts', FP Essentials. 445 17-23. (2016).

65. M.F. Marmor, 'Ophthalmology and Art: Simulation of Monet's Cataracts and Degas' Retinal Disease', Arch Ophthalmol. 124(12) 1764-1769. (December 2006).

66. Royal National Institute of Blind People, 'Understanding age-related macular degeneration', https://www.rcophth.ac.uk/wp-content/uploads/2017/10/2017-Understanding-AMD.pdf [Last accessed on 13 September 2021].

67. Royal National Institute of Blind People, 'Understanding glaucoma', https://www.rnib.org.uk/sites/default/files/Understanding_Glaucoma.pdf [Last accessed on 13 September 2021].

68. National Disability Authority, 'What is Universal Design', https://universaldesign.ie/What-isUniversal-Design/ [Last accessed on 16 August 2021].

69. Processing Foundation, 'Processing', https://processing.org/ [Last accessed on 07 October 2021].

70. G.E. Legge, 'Reading with Low Vision', Visible Language. 50(2) 102-125. (August 2016).

71. D. Kulezic-Wilson, Sound Design is the New Score, Oxford University Press, 20-21. (2020). 
72. W.A. IJsselsteijn and G. Riva, Being there: The experience of presence in mediated environments, in G. Riva, F. Davide and W.A. IJsselsteijn (eds), Being there: Concepts, effects and measurements of user presence in synthetic environments, IOS Press. 2003.

73. C. Spence, 'Olfactory-colour crossmodal correspondences in art, science, and design', Cognition Research. 5(52). (2020).

74. C. Spence, 'Musical Scents: On the Surprising Absence of Scented Musical/Auditory Events, Entertainments, and Experiences', i-Perception. (September 2021). 